\title{
As representações sociais sobre o esporte para os profissionais do programa Segundo Tempo no Mais Educação: o 'social' em evidência
}

Social representations of sports by the professionals involved in the program Segundo Tempo no Mais Educação (more education second half): the 'social' aspect in evidence

Las representaciones sociales sobre el deporte para los profesionales del programa Segundo tempo no Mais Educação: el 'social' en evidencia

\author{
Diego Petyk de Sousa ${ }^{\mathrm{I}}$, Erica Fernanda de Paula ${ }^{\mathrm{II}}$, Constantino Ribeiro de Oliveira Junior ${ }^{\mathrm{III}}$, Alfredo \\ Cesar Antunes ${ }^{\mathrm{IV}}$
}

\section{Resumo}

Considerando a existência de diferentes entendimentos sobre esporte, objetivamos identificar as representações sociais sobre esporte para os profissionais do Programa Segundo Tempo no Mais Educação de Ponta Grossa/PR. Para tanto, utilizamos dos recursos da teoria das representações sociais. Como fonte de dados, aplicamos 16 questionários aos profissionais atuantes no programa, no período de 2015. No processo de interpretação dos dados, recorremos ao software Iramuteq, adotando as estratégias analíticas da nuvem de palavras e análise de similitude. Desse modo, observamos que o núcleo central está na expressão de valores sociais e nas dimensões sociais do esporte.

Palavras-chave: Política Pública; Valores Sociais; Esportes

\begin{abstract}
Considering the existence of different understandings of sports, this study aimed to identify the social representations of sports by the professionals involved in Segundo Tempo no Mais Educação Program, in Ponta Grossa/PR. Thus, we used the Social Representations Theory in the research. As s data source, we applied 16 questionnaires to the professionals that worked in the program, in 2015. In the process of data interpretation, we used the Iramuteq Software, adopting the analytical strategies of the word cloud and the similarity analysis. Thus, we observed that the central nucleus is in the expression of social values and in the social dimensions of sport.
\end{abstract}

Keywords: Public Policy; Social Values; Sports

\footnotetext{
I Universidade Estadual de Ponta Grossa - UEPG e Centro Universitário de Maringá - UNICESUMAR - Ponta Grossa, PR, Brasil - Endereço: Avenida Carlos Cavalcanti, 5775, 28b, Uvaranas, Ponta Grossa, PR, Brasil - e-mail: diegopetyk@gmail.com

${ }^{\text {II } U n i v e r s i d a d e ~ E s t a d u a l ~ d e ~ P o n t a ~ G r o s s a ~-~ U E P G ~-~ P o n t a ~ G r o s s a, ~ P R, ~ B r a s i l ~-~ e-m a i l: ~ e r y d e p a u l a @ ~ h o t m a i l . c o m ~}$

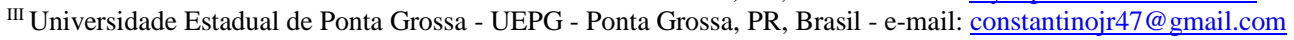

${ }^{\text {IV }}$ Universidade Estadual de Ponta Grossa - UEPG - Ponta Grossa, PR, Brasil - e-mail: alfredo.cesar@hotmail.com
} 


\section{Resumen}

Considerando la existencia de distintos entendimientos sobre deporte, objetivamos identificar las representaciones sociales sobre deporte para los profesionales del Programa Segundo Tiempo en el Más Educación de Ponta Grossa/PR. Para tanto, utilizamos de los recursos de la teoría de las representaciones sociales. Como fuente de datos, aplicamos 16 cuestionarios a los profesionales actuantes en el programa, en el período de 2015. En el proceso de interpretación de los datos, recurrimos al software Iramuteq, adoptando las estrategias analíticas de la nube de palabras y análisis de similitud. De ese modo, observamos que el núcleo central está en la expresión de valores sociales y en las dimensiones sociales del deporte.

Palavras clave: Política Pública; Valores Sociales; Deportes

\section{Introdução}

O Programa Segundo Tempo (PST) foi criado pela Portaria Interministerial $\mathrm{n}^{\circ} 3.497$ de 24 de novembro de 2003. Essa criação sinaliza um protocolo de intenções entre o Ministério do Esporte (ME) ${ }^{1} \mathrm{e}$ o Ministério da Educação (MEC) para a execução de Políticas Públicas de Esporte e Lazer (PPEL) para crianças e adolescentes ${ }^{2}$.

Desde a criação do PST, o ME procurava agregar as PPEL com a política educacional, visando incentivar a prática esportiva dentro das escolas brasileiras. Essa parceria foi instituída pela Portaria Interministerial $n^{\circ} 17$ de 24 de abril de 2007, a qual objetivou a criação do Programa Mais Educação (PME). Destacamos especialmente o Macrocampo Esporte e Lazer, ao qual o PST está vinculado. Assim, surgiu a nomenclatura Programa Segundo Tempo no Mais Educação (PSTME), para designar o funcionamento do PST dentro do PME.

O PST e seus desdobramentos ${ }^{3}$ foi estudado no campo acadêmico/científico por meio de investigações que focam equipes colaboradoras (STAREPRAVO et al., 2012), aspectos políticos (SANTOS, 2012), implementação (SOUZA; SOUZA; CASTRO, 2013), formação continuada (BICONSINI et al., 2015; OLIVEIRA et al., 2016), prática pedagógica (ARAÚJO et al., 2012; COLOMBO et al., 2012; REIS; OLIVEIRA, 2015), aspectos institucionais (ENGELMAN; OLIVEIRA, 2012; MATIAS, 2013; SANTOS, 2013, 2016), avaliação nacional do programa (REVERDITO et al., 2016) e avaliação regional do programa (SANTOS; ANDRADE; SANTOS, 2014; SANTOS,

\footnotetext{
${ }^{1}$ O Ministério do Esporte foi extinto por meio da Medida Provisória $\mathrm{n}^{\circ} 870$ de 01 de janeiro de 2019, posteriormente convertida na Lei $\mathrm{n}^{\circ}$ 13.844 de 18 de junho de 2019, que estabeleceu a organização básica dos órgãos da Presidência da República e dos Ministérios. Nessa legislação, o esporte ficou sob a responsabilidade do Ministério da Cidadania, por meio da Secretaria Especial do Esporte.

${ }^{2}$ Compreendemos crianças e adolescentes para este estudo conforme o Estatuto da Criança e do Adolescente (Lei no 8.069 de 13 de julho de 1990). No artigo $2^{\circ}$, a criança é definida como a pessoa até 12 anos de idade incompletos, e o adolescente aquela pessoa entre 12 e 18 anos de 18 anos de idade. Tal definição é a base para a formulação de Políticas Públicas no Brasil.

${ }^{3}$ Por desdobramentos do PST entendemos as suas diferentes nomenclaturas com o passar dos anos e a vinculação com outros programas do governo federal. Exemplos são: PST Universitário, PST para desporto, PST no Mais Educação e esporte na escola.
} 
STAREPRAVO; SOUZA NETO, 2015). Com base nos estudos encontrados sobre o PST e seus desdobramentos, identificamos como lacuna estudos que contemplem o entendimento de esporte para os sujeitos que atuam cotidianamente no programa. Dessa forma, surge a seguinte indagação: como os profissionais do Programa Segundo Tempo no Mais Educação de Ponta Grossa/PR entendem esporte?

Para responder essa indagação, recorremos à Teoria das Representações Sociais (TRS). O termo Representação Social (RS) foi inaugurado por Serge Moscovici em 1961, para nominar o tipo de fenômeno interpretado por essa teoria. Para Sá (1998), a TRS de Moscovici se desdobra em três correntes teóricas complementares: abordagem processual de Jodelet - mais fiel às proposições iniciais de Moscovici -, abordagem estruturalista de Abric e abordagem societal de Doise.

Uma das definições correntes no meio acadêmico é a de Jodelet (2001, p.22), entendendo as RS como "uma forma de conhecimento, socialmente elaborada e partilhada, com um objetivo prático, e que contribui para a construção de uma realidade comum a um conjunto social”.

Para Moscovici (2011, p. 61), há dois processos interdependentes que geram Representações Sociais: a ancoragem e a objetivação. A ancoragem consiste em transformar "algo estranho e perturbador, que nos intriga", e comparar com algo que já era familiar, para, então, o classificar e nomear.

A partir do processo de ancoragem, a "objetivação une a ideia de não-familiaridade com a de realidade, torna-se a verdadeira essência da realidade. [...] objetivar é descobrir a qualidade icônica de uma ideia, ou ser impreciso, é reproduzir um conceito em uma imagem" (MOSCOVICI, 2011, p.71-72). Resultando, assim, em uma representação social.

Entre as correntes teóricas complementares, Abric (2000) foi o único que criou uma nova teoria, porém, o autor deixa claro que seu entendimento de RS parte da noção elaborada por Moscovici. A teoria do Núcleo Central (TNC) de Abric (2000) entende que as RS se organizam em sistema central e periférico. O núcleo central (NC) é caracterizado pelos elementos mais estáveis das RS, enquanto os elementos periféricos são os mais suscetíveis à mudança. Abric (2000) entende ainda que a Representação Social é um guia para a ação, pois orienta as relações sociais.

Assim, este estudo objetiva: identificar as representações sociais sobre esporte para os profissionais que atuaram no Programa Segundo Tempo no Mais Educação de Ponta Grossa/PR em 2015.

\section{A construção do objeto de pesquisa: escolhas teórico-metodológicas}


Por metodologia entendemos como o caminho do pensamento e a prática de uma pesquisa, a qual inclui o método, as técnicas e a criatividade do pesquisador (MINAYO, 2012). Na busca de uma articulação entre os pontos destacados por Minayo (2012) e a TRS, optamos pelos indicativos de Sá (1998) para a construção do objeto de pesquisa em RS. A noção de 'construção do objeto de pesquisa' de Sá (1998) abrange considerações sobre o fenômeno a ser investigado, o campo de estudo, o referencial teórico utilizado e a eleição de métodos e técnicas.

Sá (1998) diferencia o fenômeno e objeto. Os fenômenos de RS estão nas práticas sociais, nas comunicações interpessoais e de massa, nos pensamentos, nas instituições, na cultura, entre outros. Enquanto os fenômenos são construídos no que Moscovici chama de universos consensuais de pensamento, os objetos são elaborados no universo reificado da ciência. Do mesmo modo, o fenômeno é a RS, enquanto o objeto é o conteúdo da pesquisa científica. Logo, é necessário transformar conceitualmente o fenômeno do universo consensual em um problema científico do universo reificado. Para Sá (1998, p. 23), “[...] numa primeira aproximação, podemos dizer que a construção do objeto de pesquisa é um processo pelo qual o fenômeno de representação social é simplificado e tornado compreensível pela teoria, para finalidades da pesquisa”.

Sá (1998) alerta que o processo de simplificação citado é razoavelmente complexo e difícil, porém algumas proposições da TRS auxiliam essa fase de construção. Nesse sentido, o autor evoca a máxima de Jodelet, de que uma RS é sempre de alguém (sujeito) e de alguma coisa (objeto), sendo que não é possível falar em RS sem especificar o sujeito, que pode ser uma população ou conjunto social, que mantém a referida representação.

Desse modo, definimos como objeto do estudo o esporte e como sujeitos os profissionais do Programa Segundo Tempo no Mais Educação (PSTME) de Ponta Grossa/PR, os quais são os responsáveis pela execução e implementação do programa. Para a seleção dos sujeitos participantes usamos os seguintes critérios: a) dentro dos colégios estaduais participantes, os dois que foram contemplados há mais tempo com o PST no Mais Educação; b) dentro das escolas municipais participantes, as duas que foram contempladas há mais tempo com o PST no Mais Educação; c) os profissionais que atuam/atuaram no Programa Segundo Tempo, no mínimo por um período de 6 meses; d) a equipe gestora da Secretaria Municipal de Educação de Ponta Grossa.

Nas localidades entramos em contato com as diretorias para explicar os objetivos da pesquisa, entrega dos questionários e o Termo de Consentimento Livre e Esclarecido. A participação na pesquisa 
por parte dos sujeitos foi por adesão. Depois do período de coleta que foi entre março e maio de 2015, obtivemos o retorno de 16 questionários respondidos.

Para a análise dos 16 questionários, utilizamos o Software Interface de $R$ pour les nalyses Multidimensionnelles de Textes et de Questionnaires (IRAMUTEQ). O Software foi desenvolvido por Pierre Ratinaud, sendo empregado inicialmente em língua francesa. No Brasil ${ }^{4}$, passou a ser utilizado a partir de 2013 (CAMARGO; JUSTO, 2013).

O IRAMUTEQ é um software gratuito que permite a realização de análise de textos e evocações de palavras. A sua utilização, aliado à TRS, emerge como uma possibilidade de análise para os estudos relacionados ao esporte, nas Ciências Humanas e Sociais (PAULA; SOUSA; ANTUNES, 2018).

O Laboratório de Psicologia Social da Comunicação e Cognição (LACCOS), da Universidade Federal de Santa Catarina (UFSC), desenvolveu o dicionário em língua portuguesa para o IRAMUTEQ e organizou um "KIT IRAMUTEQ", onde disponibilizam: um tutorial elaborado por Camargo e Justo $(2018)^{6}$, em que é explicado de forma didática o processo de instalação, preparação do corpus textual e as possibilidades de análise; demais textos que tratam sobre o Software; e o link para baixar o Software R, o IRAMUTEQ e o LibreOffice, que é a ferramenta que deve ser utilizada para anexar os dados textuais no IRAMUTEQ.

O Software IRAMUTEQ possibilita desde análises simples, “[...] como a lexicografia básica (cálculo de frequência de palavras), até análises multivariadas (classificação hierárquica descendente, análises de similitude)" (CAMARGO; JUSTO, 2013, p. 515). A organização do vocabulário aparece de forma compreensível e clara.

As análises do IRAMUTEQ são realizadas a partir do corpus preparado pelo pesquisador, o qual pode ser organizado em planilhas (utilizadas para análise de evocações de palavras) ou em arquivos de texto $^{7}$. No presente estudo o material foi organizado em arquivos de texto e posteriormente analisado através de nuvem de palavras e análise de similitude.

A nuvem de palavras trata-se de uma análise lexical simples, que agrupa e organiza as palavras de acordo com a frequência, possibilitando a percepção das palavras-chave do corpus. Por outro lado, a

\footnotetext{
${ }^{4} \mathrm{O}$ uso de softwares para analisar dados textuais tem crescido nas Ciências Humanas e Sociais. No Brasil, são utilizados principalmente a partir da década de 1990 (CAMARGO; JUSTO, 2013).

${ }^{5}$ Kit Iramuteq. Disponível em: <http://www.laccos.com.br/index.php?option=com_content\&view=article\&id=208\%3Atutorial-do-softwareiramuteq-em-portugues\&catid=40\%3Aoutros\&Itemid=9\&lang=br>. Acesso em: 11 jul. 2018.

${ }^{6} \mathrm{O}$ tutorial é atualizado conforme o lançamento das novas versões do Software. O tutorial disponível atualmente é de 21 de novembro de 2018.

7 "Os textos ou tabelas devem ser preferencialmente gerados pelos softwares OpenOffice.org ou LibreOffice, para evitar bugs relativos a codificação" (CAMARGO; JUSTO, 2013, p. 516).
} 
análise de similitude organiza as palavras-chave, pois permite analisar a estrutura do conteúdo do corpus textual, identificando se há conexidade entre as palavras, sendo frequentemente utilizada por pesquisadores das representações sociais.

\section{Resultados e discussão}

Para cumprir o objetivo proposto desta pesquisa apresentamos os resultados em dois momentos. Primeiramente, focamos no perfil dos sujeitos participantes da pesquisa, posteriormente mostraremos os dados sobre o objeto da RS.

O perfil do profissional atuante no PSTME foi composto por três informações: a) formação acadêmica; b) função no programa; c) tempo de atuação no programa.

As respostas fornecidas pelos pesquisados mostram que nas localidades selecionadas, encontramos profissionais graduados em Educação Física (02), História (01), Pedagogia (11) e dois(02) graduandos em Educação Física. Sendo que dez (10) são especialistas, três (03) mestres e um (01) somente graduado.

Em relação à formação específica para atuar no programa, 18,75\% dos profissionais participantes da pesquisa relataram ter passado por alguma capacitação. Dentro dos exemplos citados de capacitação, foram lembrados cursos realizados pelo Núcleo Regional de Educação de Ponta Grossa e pela Secretaria Municipal de Educação de Ponta Grossa.

No caso estudado destacamos a não participação dos sujeitos no processo de formação continuada elaborado pelas equipes colaboradoras do PST. Esses dados são opostos da realidade encontrada nos estudos de Araújo et al. (2012) e Oliveira et al. (2016), que ressaltam a importância dos processos de formação continuada no PST para a sua boa execução. Dessa forma, inferimos que a não participação em processos de formação continuada específica para atuar no programa, poderá implicar no seu processo de implementação, impactando no cumprimento dos objetivos do programa. O que demonstra uma situação preocupante que deverá ser investigada em trabalhos futuros.

Do grupo de trabalho pesquisado, dez (10) indivíduos (62,5\%) indicaram ter a função de coordenação pedagógica. Conforme as Diretrizes do Programa Segundo Tempo, é necessário a formação em nível superior na área de Educação Física ou esporte para atuar na coordenação pedagógica do programa (BRASIL, 2011, 2014). Porém, na localidade estudada somente um profissional atendia a esse critério. Os outros nove profissionais que se enquadraram nessa função têm formação em pedagogia. Essa 
diferença entre o critério para atuar e a realidade observada também foi relatada no estudo de Araújo et al. (2012), que identificou em seu estudo que nem todos os coordenadores de núcleo tinham formação superior em Educação Física.

Acreditamos que a divergência de critério e informação prestada pelos profissionais se deve ao fato deles atuarem na coordenação pedagógica da escola ou da Secretaria Municipal de Educação e não na coordenação pedagógica específica do programa. Porém, concordamos com Araújo et al. (2012) ao entender que o fato da coordenação pedagógica do programa ser executada por um profissional de outra área pode comprometer os objetivos e metas estipuladas pelo programa.

Em relação ao tempo de atuação no programa, 62,5\% dos profissionais atuavam há mais de um ano e menos de dois anos. Levando em conta que o programa na cidade de Ponta Grossa funcionou desde o ano de 2010, somente $12,5 \%$ dos profissionais atuavam no início do seu funcionamento. Portanto, evidenciamos uma dificuldade de permanência de profissionais atuando por um longo tempo na mesma localidade.

Tendo conhecimento do perfil dos profissionais pesquisados, a seguir são apresentados os resultados identificados. Inicialmente destacamos a nuvem de palavras, a qual reúne as palavras-chaves do corpus produzido através das respostas de quatro grupos de questões referentes aos conceitos chave do PST e seus desdobramentos: a) objetivo do esporte; b) democratização; c) inclusão social; d) cidadania.

Figura 1 - Nuvem de palavras sobre o esporte para os profissionais do Programa Segundo Tempo no Mais Educação

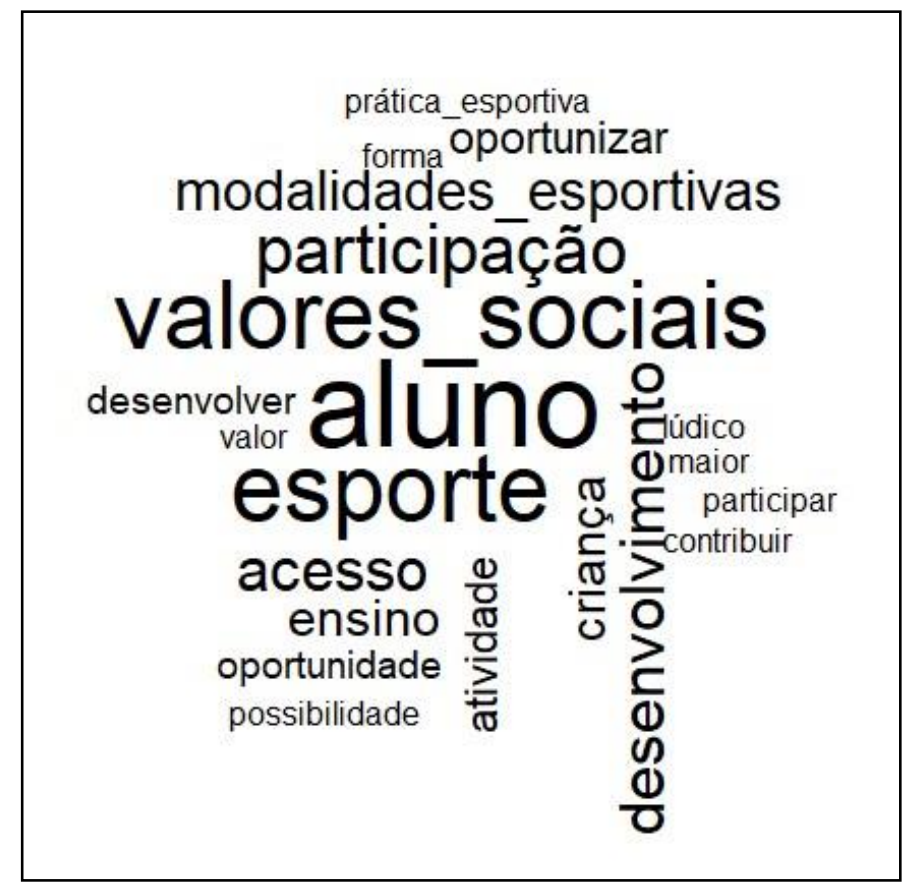

Fonte: Os autores 
As expressões valores sociais, aluno e esporte estão entre as mais frequentes. Com a nuvem de palavras é possível demonstrar os elementos estáveis e periféricos do NC da RS sobre Esporte. Portanto, o elemento estável dessa RS está na expressão de valores sociais ligados ao esporte.

Na sequência, através da análise de similitude observamos que os valores sociais são o ponto central do corpus e, a partir dele, emergem novas conexões, em que é possível identificar a coerência e a conexidade entre o conteúdo do corpus.

Figura 2 - Análise de similitude sobre o esporte para os profissionais do Programa Segundo Tempo no Mais Educação

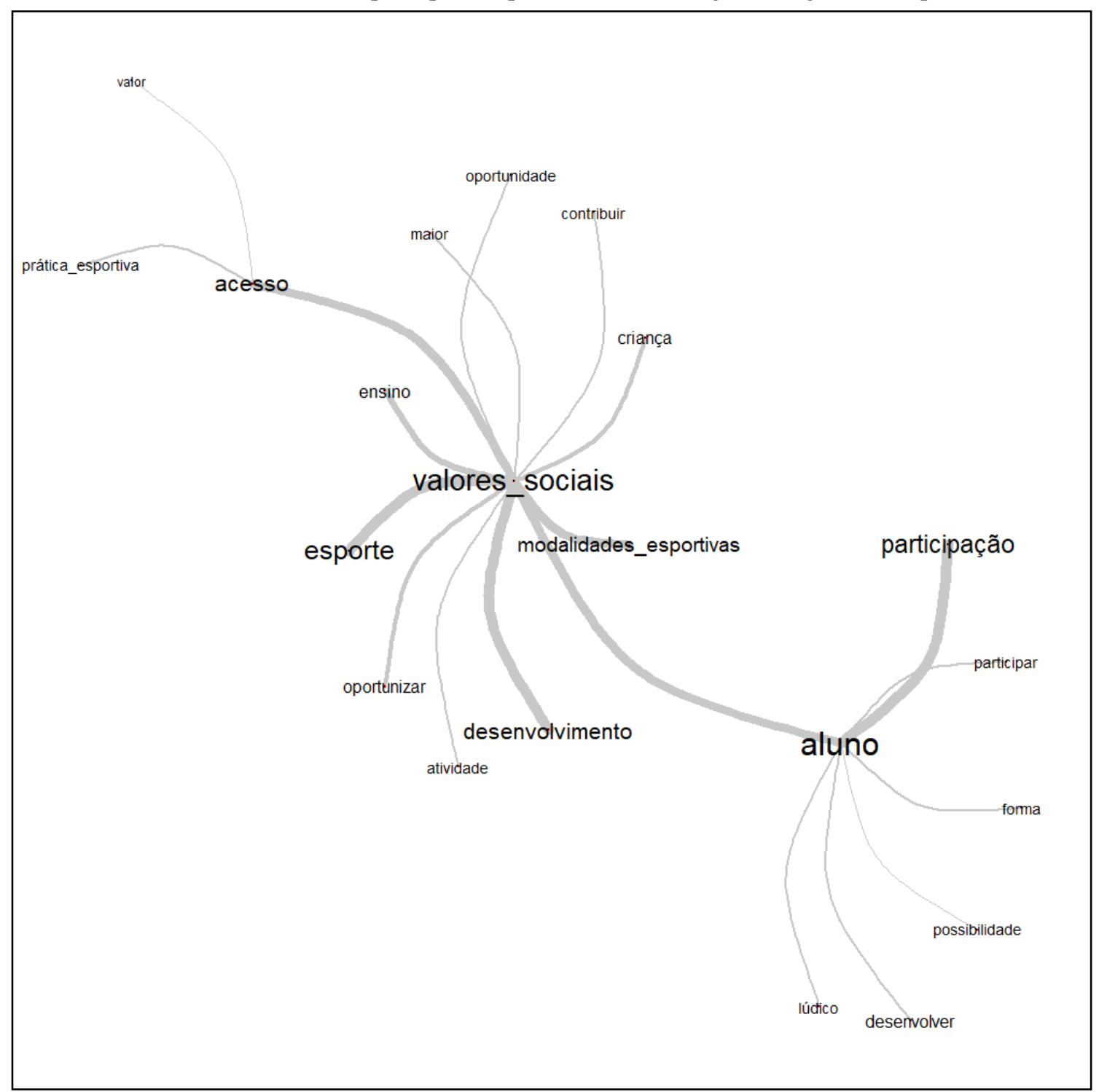

Fonte: Os autores 
Os valores sociais aparecem em destaque central da análise de similitude, sendo o ponto de partida para os demais termos. Ao longo das entrevistas, dos 16 sujeitos, 13 (81\%) utilizaram ao menos uma vez a expressão 'valores sociais' ou 'valores'.

Propicia o desenvolvimento das habilidades motoras e valores sociais. (Indivíduo 5).

Desenvolvimento de práticas que proporcionam a aprendizagem de valores sociais. Contribuindo para o processo de humanização e dando a oportunidade de conhecer novas modalidades esportivas. (Indivíduo 6).

Podemos trabalhar as modalidades esportivas auxiliando no processo de aprendizagem de valores sociais. (Indivíduo 12).

Contribui para o ensino de valores sociais. (Indivíduo 12).

Essa RS de que o esporte transmite valores sociais pode estar ancorada em um dos objetivos específicos do PST, que é o desenvolvimento de valores sociais por meio das práticas das modalidades esportivas ofertadas. Porém, a ideia de valores sociais atrelados às práticas de esporte é algo presente no senso comum das pessoas da área esportiva, essa relação indica elementos de sociabilidade por meio do esporte.

Para Stigger (2011), a classificação das dimensões sociais do esporte de Tubino teve grande difusão na área da Educação Física e esportes, esse fato pode ter contribuído para a vulgarização na sua utilização, principalmente por estar presente nos diferentes discursos da área. Ou seja, a reconceitualização do conceito de esporte proposta nos estudos de Tubino ganhou o imaginário social esportivo brasileiro. Exemplos são as suas adoções na Constituição da República Federal de 1988 e legislação esportiva, assim como conceito base nas PPEL.

Portanto, entendemos que os conceitos de Tubino influenciaram de uma forma as RS dos sujeitos participantes. Principalmente, devido o alargamento da visão do esporte para além do rendimento e caminhando para uma dimensão social do esporte.

Outro ponto muito utilizado foi o imaginário de que o esporte pode ocupar o tempo ocioso das crianças, evitando assim o envolvimento em práticas ilícitas. Exemplos de algumas situações que foram expressas:

Quem pratica esporte não tem tempo nem vontade de ir por caminhos errados. O esporte promove valores sociais. (Indivíduo 8).

As crianças ficam menos tempo ociosas o que acaba desviando-as do mal caminho. (Indivíduo 9). 
O esporte além do desenvolvimento físico e da saúde serve também para valores sociais, afastando as crianças das ruas. (Indivíduo 13).

O esporte deve ser uma prática sadia na qual afasta os jovens das drogas e do ócio. (Indivíduo 15).

Foi possível identificar por meio das falas dos indivíduos 8, 9, 13 e 15 as pretensões de proporcionar um futuro melhor para crianças e jovens. Tal compreensão destaca o caráter de controle social e a possível administração de conflitos que tem a inspiração na filosofia de manter as crianças e adolescentes longe dos males e perigos da ociosidade. Assim, o uso do esporte é pensado como uma espécie de redutor dos índices de violência e criminalidade urbana, evidenciando um padrão discursivo que associa a representação assistencialista e compensatória dos projetos sociais esportivos. Dessa forma, o padrão compartilhado é de que a rua é perigosa (MASCARENHAS, 2003; SILVEIRA, 2013, 2016; MELLO et al., 2018).

Dessa forma, entendemos que a visão de controle social evidenciada nos discursos dos sujeitos participantes está ancorada no que Souza et al. (2010) chamam de perspectiva apologistas de programas sociais esportivos. Pois, entende que os programas são capazes de proporcionar benefícios tais como integração social, combate à violência e à criminalidade, disciplinamento, prevenção do uso de drogas, promoção da saúde e construção de um futuro melhor. .

Outro ponto destacado pela análise de similitude são os termos: acesso e participação. Desse modo, no entendimento dos profissionais pesquisados, o programa favorece o processo de democratização ${ }^{8}$ do esporte. Entendido assim como um meio para oferecer oportunidades para crianças e adolescentes.

Portanto, o programa é um mecanismo de criação de espaços de oportunidade para os excluídos da formação esportiva. Assim, tal ação de inserção visa a redução de desigualdades de oportunidades. Fato que se pode aproximar dos pontos que Macpherson (1978) coloca como obstáculos para a participação, ou seja, a desigualdade social. Nesse caso, o acesso ao esporte, por meio de PPEL, seria apenas mais um elemento para contribuir na redução da desigualdade de oportunidades de formação.

Por fim, a criação de oportunidades oferecida pelo programa na visão dos profissionais pesquisados favorece o processo de democratização do esporte no momento que expande a oferta de

\footnotetext{
${ }^{8}$ Destacamos que o sentido do termo 'democratização' empregado no texto é a representação social dos sujeitos pesquisados sobre o termo. Dessa forma, para uma discussão ampliada sobre os significados que esse termo tem na literatura sobre projetos sociais, ver Sousa; Antunes (2014); Sousa (2015).
} 
oportunidades ao esporte para crianças e adolescentes até então excluídos das possibilidades de participação nas práticas esportivas.

Compreendemos que a TRS pode auxiliar no entendimento dos discursos dos atuantes no PST e seus desdobramentos. Porém, a constatação de que a RS tem como NC as expressões de "valores sociais" e "controle social" é a mesma indicada pela literatura sobre os diferentes projetos sociais esportivos. O que reforça o argumento de Mello et al. (2018) ao destacarem que esses discursos, do ponto de vista moral, estão cristalizados no senso comum sobre os projetos sociais esportivos, sendo inquestionável a sua função de retirar crianças e adolescentes da rua e a promoção de valores sociais.

Dessa forma, a limitação do presente estudo e também da área está na dificuldade de entender o adjetivo 'social'. Exemplos são as expressões comuns que usamos como 'valores sociais', 'controle social', 'dimensões sociais do esporte', entre outros. Essa dificuldade já foi relatada por Latour (2012) ao questionar o entendimento do 'social' a um fenômeno qualquer. Essa busca para compreender o que realmente é o ‘social' nas PPEL será o próximo desafio que pretendemos resolver.

\section{Conclusão}

Esta pesquisa visou identificar as Representações Sociais sobre Esporte para os profissionais que atuaram no Programa Segundo Tempo no Mais Educação de Ponta Grossa/PR. Dessa forma, evidenciamos, no presente estudo, a falta de formação continuada específica para atuar no programa. Isso poderá impactar no processo de implementação do programa na localidade estudada.

Outro ponto destacado é que identificamos como Núcleo Central da RS de esporte a expressão 'valores sociais'. Como elementos periféricos, encontramos as expressões 'acesso' e 'participação'. Assim, os elementos centrais e periféricos não diferenciam do que a literatura coloca sobre os projetos sociais esportivos.

Portanto, precisamos avançar no entendimento da expressão 'social' na área de Educação Física e esporte, pois o adjetivo 'social', como está sendo utilizado até agora, não esclarece qual o significado atribuído. 


\section{Referências}

ABRIC, Jean-Claude. A abordagem estrutural das representações sociais. In: MOREIRA, A. S. P.; OLIVEIRA, D. C. (Org.). Estudos interdisciplinares de representação social. 2. ed. Goiânia: AB, 2000. p. 27-37.

ARAUUJO, Alysson Carvalho de. et al. Formação e atuação pedagógica no Programa Segundo Tempo: reflexões sobre o fazer cotidiano do professor. Motrivivência, Florianópolis, v.24, n. 38, p. 40-58, jun. 2012. Disponível em: < https://periodicos.ufsc.br/index.php/motrivivencia/article/view/21758042.2012v24n38p40>. Acesso em: 30 jun. 2018.

BRASIL. Estatuto da Criança e do Adolescente $n^{\circ}$ 8069, de 13 de julho de 1990. Dispõe Sobre O Estatuto da Criança e do Adolescente e Dá Outras Providências.. Brasília, DF, Disponível em: http://www.planalto.gov.br/ccivil_03/leis/18069.htm. Acesso em: 05 Mar. de 2020.

BRASIL. Portaria Interministerial No 3.497, de 24 de Novembro de 2003. Protocolo de Intenções que celebraram o Ministério do Esporte - ME e o Ministério da Educação - MEC, visando a execução de programas relacionados ao esporte no ensino fundamental. Disponível em: <http://portal.mec.gov.br/sesu/arquivos/pdf/port3497.pdf>. Acesso em 05 de Mar. de 2020.

BRASIL. Portaria Interministerial $n^{\circ}$ 17, de 24 de abril de 2007. Institui o Programa Mais Educação, que visa fomentar a educação integral de crianças, adolescentes e jovens, por meio do apoio a atividades sócio-educativas no contraturno escolar. Disponível em: http://www.abmes.org.br/abmes/public/arquivos/legislacoes/Port_Norm_Inter_017_2007_04_24.pdf.

Acesso em: 05 de mar. de 2020.

BRASIL. Programa Segundo Tempo (2014). Diretrizes do Programa Segundo Tempo. Brasília: Ministério do $\quad$ Esporte, $2014 . \quad$ Disponível em: <http://www.esporte.gov.br/arquivos/snelis/segundoTempo/diretrizesPSTPadrao2014.pdf>. Acesso em 30 jun. 2018.

BRASIL. Programa Segundo Tempo (2011). Diretrizes do Programa Segundo Tempo. Brasília: Ministério do $\quad$ Esporte, 2011.20 Disponível 〈http://www.esporte.gov.br/arquivos/snelis/segundoTempo/DiretrizesdoProgramaSegundoTempo.pdf $>$. Acesso em 30 jun. 2018.

BRASIL. Rede de saberes mais educação (2009). Pressupostos para projetos pedagógicos de educação integral: caderno para professores e diretores de escolas. Disponível em: <http://portal.mec.gov.br/dmdocuments/cad_mais_educacao.pdf>. Acesso em: 30 jun. 2018.

BRASIL. Medida Provisória $n^{\circ}$ 870, de 1 de janeiro de 2019. Estabelece a Organização Básica dos órgãos da Presidência da República e dos Ministérios.. Brasília, DF, Disponível em: <http://www.planalto.gov.br/ccivil_03/_Ato2019-2022/2019/Mpv/mpv870.htm>. Acesso em: 05 mar. 2020.

CAMARGO, Brigido Vizeu.; JUSTO, Ana Maria. IRAMUTEQ: um software gratuito para análise de dados textuais. Temas em Psicologia, Ribeirão Preto, v.21, n.2, p. 513-518, dez. 2013. Disponível em: 
<http://pepsic.bvsalud.org/scielo.php?script=sci_arttext\&pid=S1413-

389X2013000200016\&lng=pt\&nrm=iso>. Acesso em: 11 jul. 2018.

CAMARGO, Brigido Vizeu; JUSTO, Ana. Maria. Tutorial para o uso do Software IRAMUTEQ. 2018. Disponível em: <https://drive.google.com/drive/u/1/folders/0B1sJtjYHLc94fjFPZThMMIZEZkVIQV9fdU5nLUpBQ29n YVAtUU5RSm5Hc3M2TGhHYUFLQUk>. Acesso em: 10 ago. 2019.

COLOMBO, Bruno Dandolini. et al. O programa segundo tempo: uma política pública para emancipação humana. Motrivivência, Florianópolis, n. 38, p. 12-23, set. 2012. Disponível em: <https://periodicos.ufsc.br/index.php/motrivivencia/article/view/2175-8042.2012v24n38p12>. Acesso em: 30 jun. 2018.

ENGELMAN, Selda; OLIVEIRA, Amauri Aparecido Bassoli de. Gestão Pública em Rede: o caso do programa segundo tempo - Ministério dos Esportes. Rev. Educ. Fis/UEM, Maringá, v. 23, n. 4, p. 543552, $\quad$ out./dez. $2012 . \quad$ Disponível em: <http://www.periodicos.uem.br/ojs/index.php/RevEducFis/article/view/13379>. Acesso em: 30 jun. 2018.

JODELET, Denise. Representações sociais: um domínio em expansão. IN: JODELET, D. (Org.). As representações sociais. Rio de Janeiro: UERJ, 2001, p. 17-44.

LATOUR, Bruno. Reagregando o social: uma introdução à teoria do ator-rede. Salvador: Edufba, São Paulo: Edusc, 2012.

MACPHERSON, Crawford Brough A Democracia Liberal: origens e evolução. Rio de Janeiro: Zahar,1978.

MASCARENHAS, Fernando. O pedaço sitiado: cidade, cultura e lazer em tempos de globalização. Revista Brasileira de Ciências do Esporte, Campinas, v. 24, n. 3, p. 121-143, maio 2003. Disponível em: 〈http://revista.cbce.org.br/index.php/RBCE/article/view/767/441>. Acesso em: 30 jun. 2018.

MATIAS, Wagner Barbosa. A Política Esportiva do Governo Lula: o Programa Segundo Tempo. Licere, Belo Horizonte, v.16, n.1, mar. 2013. Disponível em: <https://seer.ufmg.br/index.php/licere/article/view/412/307>. Acesso em: 30 jun. 2018.

MELLO, André da Silva. et al. Representações sociais dos participantes de projeto esportivo de vitória. Movimento, Porto Alegre, p. 399-412, jun. 2018. Disponível em: <http://www.seer.ufrgs.br/index.php/Movimento/article/view/65543 >. Acesso em: 24 jul. 2018.

MINAYO, Maria Cecília de Souza. O desafio da pesquisa Social. In: MINAYO, M. C. S(Org) Pesquisa Social: teoria, método e criatividade. 31 ed. Petrópolis: Vozes, 2012.

MOSCOVICI, Serge. Representações sociais: investigações em psicologia social. 8.ed. Petrópolis, RJ: Vozes, 2011. 
OLIVEIRA, Amauri Aparecido Bassoli de. et al. Formação continuada em projetos e programas sociais esportivos: um estudo de caso. Movimento, Porto Alegre, v. 22, n. 3, p. 901-916, jul./set. 2016. Disponível em: <http://www.seer.ufrgs.br/index.php/Movimento/article/view/57304>. Acesso em: 30 ago. 2018.

PAULA, Érica Fernanda de; SOUSA, Diego Petyk de; ANTUNES, Alfredo Cesar. Teoria das Representações Sociais e software IRAMUTEQ: Uma Possibilidade Metodológica para Estudos nas Ciências Sociais e Humanas. In: FREITAS JUNIOR, Miguel Archanjo de; RAUSKI, Eliane de Fátima (Org.). Possibilidades Metodológicas para a Abordagem do Esporte nas Ciências Sociais. Ponta Grossa: Texto e Contexto, 2018. Cap. 4. p. 77-105.

REIS, Lorena Nabanete dos.; OLIVEIRA, Amauri Aparecido Bassoli de. A ginástica no programa segundo tempo: desafios e possibilidades da prática em programas sociais. Conexões, Campinas, SP, p. 39-57, maio 2015. ISSN 1983-9030. Disponível em: <https://periodicos.sbu.unicamp.br/ojs/index.php/conexoes/article/view/8637575>. Acesso em: 30 ago. 2018.

REVERDITO, Riller Silva. et al. O Programa Segundo Tempo em municípios brasileiros: indicadores de resultado no macrossistema. J. Phys. Educ. v, 27, p. 2754, 2016. Disponível em: < http://periodicos.uem.br/ojs/index.php/RevEducFis/article/view/31303/18006>. Acesso em: 30 jun. 2018.

SÁ, Celso. Pereira de. A construção do objeto de pesquisa em representações sociais. Rio de Janeiro: EdUERJ, 1998. 110p.

SANTOS, Edmilson Santos dos. As coalizões e os partidos políticos na difusão do Programa Segundo tempo. Licere, Belo Horizonte, v.15, n.3, set. 2012. Disponível em: <https://seer.ufmg.br/index.php/licere/article/view/437>. Acesso em: 30 jun. 2018.

SANTOS, Edmilson Santos dos. Ambiente institucional e difusão do Programa Segundo Tempo: uma análise da difusão regional de 2005 a 2009. Pensar a Prática, Goiânia, v. 16, n. 1, p. 1319, jan./mar. 2013. Disponível em: <https://www.revistas.ufg.br/fef/article/view/15535>. Acesso em: 30 jun. 2018.

SANTOS, Edmilson Santos dos. Governo do Estado e descentralização do Programa Segundo Tempo. Pensar a Prática, Goiânia, v. 19, n. 2, abr./jun. 2016. Disponível em: <https://www.revistas.ufg.br/fef/article/view/39038>. Acesso em: 30 jun. 2018.

SANTOS, Edmilson Santos dos.; ANDRADE, Jean Carlo; SANTOS, Roberto Silva. Programa Segundo Tempo e o papel das prefeituras na sua difusão. Pensar a Prática, Goiânia, v. 17, n. 4, out./dez. 2014. Disponível em: <https://www.revistas.ufg.br/fef/article/view/29020>. Acesso em: 30 jun. 2018.

SANTOS, Edmilson Santos dos.; STAREPRAVO, Fernando Augusto.; SOUZA NETO, Marina da Silva. Programa "Segundo Tempo" e o vazio assistencial na Região Nordeste. Movimento, Porto Alegre, v. 21, n. 3., p. 759-771, jul./set. de 2015. Disponível em: < http://www.seer.ufrgs.br/index.php/Movimento/article/view/50648>. Acesso em: 30 jun. 2018.

SILVEIRA, Juliano. Considerações sobre o esporte e o lazer: entre direitos sociais e projetos sociais. Licere, Belo Horizonte, v.16, n.1, mar/2013. Disponível em: 〈https://seer.ufmg.br/index.php/licere/article/view/413〉. Acesso em: 20 jul. 2018. 
SILVEIRA, Juliano. O esporte da/na escola nas políticas públicas em Santa Catarina. Kinesis, Santa Maria, v. 34, ago. 2016.. Disponível em: 〈https://periodicos.ufsm.br/kinesis/article/view/21707>. Acesso em: 31 out. 2018.

SOUSA, Diego Petyk de; ANTUNES, Alfredo Cesar. Apontamentos entre concepções contemporâneas de democracia e o Programa Segundo Tempo: um estudo inicial. Lecturas Educación Física y Deportes, Buenos Aires, v. 194, n. 19, p.1-1, jul. 2014. Disponível em: <https://www.efdeportes.com/efd194/concepcoes-contemporaneas-de-democracia-e-pst.htm>. Acesso em: 10 ago. 2019.

SOUSA, Diego Petyk de. O Programa Segundo Tempo no Mais Educação entre documentos e discursos: os casos dos profissionais de Ponta Grossa - Paraná. 2015, 129 f. Dissertação (Mestrado em Ciências Sociais Aplicadas) - Universidade Estadual de Ponta Grossa, Ponta Grossa, 2015. Disponível em: <http://bicen-tede.uepg.br/tde_busca/arquivo.php?codArquivo=1445>. Acesso em: 10 abr. 2018.

SOUZA, Ana Paula Prestes de.; SOUZA, Doralice Lange de; CASTRO, Suelen Barboza Eiras de. Barreiras e facilitadores para a implementação do Programa Segundo Tempo: um estudo de caso. Pensar a Prática, Goiânia, v. 16, n. 4, p. 956-1270, out./dez. 2013. Disponível em: <https://www.revistas.ufg.br/fef/article/view/20113>. Acesso em: 30 jun. 2018.

SOUZA, Doralice Lange de. et al. Determinantes para a implementação de um projeto social. Motriz, Rio Claro, v. 16, n. 3, p. 689-700, jul./set. 2010. Disponível em: <http://www.scielo.br/pdf/motriz/v16n3/a17v16n3.pdf>. Acesso em: 20 jul. 2018.

STAREPRAVO, Fernando Augusto. et al. As equipes colaboradoras do Programa Segundo Tempo e suas contribuições para o desenvolvimento de uma política de esporte educacional. Motrivivência, Florianópolis, $\quad$ n. $24, \quad$ n. 39, dez. 2012. Disponível em: <https://periodicos.ufsc.br/index.php/motrivivencia/article/view/2175-8042.2012v24n39p129>. Acesso em: 30 jun. 2018.

STIGGER, Marco Paulo. Educação física: esporte e diversidade. 2. Ed. rev. Campinas: Autores Associados, 2011.

\section{Como citar este artigo}

SOUSA, D. P.; PAULA, E. F.; OLIVEIRA JUNIOR, C. R.; ANTUNES, A. C. As representações sociais sobre o esporte para os profissionais do programa segundo tempo no mais educação: o 'social' em evidência. Revista Kinesis, Santa Maria, v. 38, p. 1-16, 2020. 
* O presente trabalho foi realizado com apoio da Coordenação de Aperfeiçoamento de Pessoal de Nível Superior - Brasil (CAPES) - Código de Financiamento 001. 